\title{
Learning Through Participation: "The Willingness To Join In And Be Changed By A Common Dance" Connie Bethards
}

\begin{abstract}
Building a true life, according to Martin Buber, comes from entering into mutuality, an encounter with the world in which there is mutual recognition and confirmation. Mutuality depends upon the fullness of human participation in encounters with others. Buber called for genuine dialogue "where each of the participants really has in mind the other or others in their present and particular being and turns to them with the intention of establishing a living mutual relation between himself and them" (1955, p. 19). In this mutuality humans are open to being changed.

Buber's concept of mutuality resonates within the writing of Mary Catherine Bateson. She saw personhood "as something that comes into being and grows through relationship and participation" (p. 61). She wrote:

Membership in a human family or community is an artifact, something that has to be made, not a biological given. Membership both acknowledges and bridges separateness, for it is constructed across a gap of mutual incomprehension, depending always on the willingness to join in and be changed by a common dance. Western culture associates independence and autonomy with strength, but there is a sense in which an awareness of being part of a larger whole, of being defined by context, a self in adaptation, can offer a different strength, leading to flexibility and constant learning. (1994, p.62).
\end{abstract}

Bateson's phrase, "the willingness to join in and be changed by a common dance," comes to mind as I recall some of the experiences I had as co-director and art teacher for the Close Encounters Art Workshop, a two-week summer residential camp for teenagers with physical disabilities. Teens attended Close Encounters to develop supportive friendships with others who have disabilities. Participants had the opportunity to increase their freedom and become aware of and use community resources. The program took place within a university setting where participants were involved in art making with artist mentors.

The issue of social acceptance was a familiar challenge for the Close Encounters participants because all nine of them had experienced to some extent the isolation and loneliness resulting from not playing a part in the social life of their schools. Even though they had all been included, to one degree or another, in the regular classrooms with their nondisabled peers, being placed in the same classroom does not necessarily ensure "social benefits to either group" (Gottlieb in Maddy, 1988, p.49). It is paradoxical that when "the need for acceptance is at its developmental peak, ... peer rejection of the adolescent [with disabilities] is most intense" (Cobb \& Hancock in Maddy, p. 50). 
One morning as the Close Encounter participants settled in at the computer lab preparing to resume work on their self portraits, I stood back and observed Jay for a few minutes. He positioned his wheelchair in front of a computer station right next to David. Side by side, they presented a study in contrasts. David, the popular young leader at camp, seemed equally at ease in academic or social situations while Jay, often the loner, kept a safe distance from others and struggled with learning new concepts. David's social competency served as a springboard to opportunities for inclusion with his peers. Jay's underdeveloped social skills frequently prevented him from establishing membership in adolescent social groups.

Jay was one participant who we were warned might not last the entire two weeks of the camp. It was his mother's idea for Jay to attend camp. Fearing his growing dependence on her, she hoped that at camp he might learn to be more self sufficient and make friends with other teens who experience disabilities. Jay's mother thought if she could just get him to come to camp he would probably stay. Jay is seventeen, has Spina Bifuda and primarily uses a wheelchair for mobility. $\mathrm{He}$ felt especially self conscious about his need to catheterize and before attending camp, had no other friends or acquaintances who use catheterization.

One evening earlier in the week after a pizza party, Jay had lingered behind as the other Close Encounter participants made their way out of Happy Joe's and found a seat on the Bionic Bus. His mood was not unlike the first time I had met him during a Sunday afternoon orientation session. Then he was quiet not volunteering any comments and responding only if directly addressed. When he spoke, his facial expression changed very little and he remained so motionless in his wheelchair it seemed as if he were trying to become invisible. I asked Jay if he had brought any photographs, art work or other favorite images to scan into the computer for the self portrait project we would be doing during the art making sessions. He shook his head saying he had forgotten all about the photographs because of an emergency with his chocolate Labrador puppy. Right before leaving for camp, Jay's puppy became so ill that the family rushed him to the veterinarian's. Jay worried that the puppy might die while he was at Close Encounters. With that disclosure, I understood at least part of the reason for Jay's forlorn demeanor and suggested he call home on a regular basis to check on his puppy's progress.

When Jay made no attempt to leave Happy Joe's and join the other participants on the bus, I sat down beside him wondering what he might be thinking. With tears in his eyes and no special prompting from me, he confessed he was not having such a good time at camp. He thought the other teenagers didn't like him. Something in his defeated expression reminded me of my son's habit of never discussing problems until it was late enough at night for him to reach a certain threshold of misery. I told Jay a story about my son's repeated attempts to skip school. Like Jay, he was also very shy and had difficulty making friends after we moved to a new town. I explained that people who are shy sometimes appear to be unfriendly. I offered him the very same suggestions I had urged my son to practice about ten years earlier: look people in the eye, smile once in while, show an interest in what others are doing by asking them questions; in short, try to meet 
people at least halfway when starting new friendships. I assured him that my son had learned to make friends and he could too.

As we talked, Linda, the other co-director of the camp, had overheard most of our dialogue and went out to the bus where the other participants were now seated. She told them that Jay was not yet feeling a part of the group and asked for ideas about how to help him feel more included. An immediate response came from David who volunteered to invite Jay to play pool with the guys when they returned to the dorm.

The morning I observed Jay in the computer lab, I was relieved to find out that he had decided to remain at camp. Playing pool with the guys had helped to change his mind about going home. I watched as Jay loaded his zip disc and opened up his file in Photoshop to view several images he had worked on the day before. Prior to coming to camp, Jay had little experience with computers. I knew from reading the clinical notes on Jay that he had a number of learning disabilities that might interfere with his acquisition of computer skills. However, I had learned from my previous experiences in teaching art to children with communication disorders and learning disabilities, not to limit my expectations of what they could achieve but rather to focus on their strengths and interests. I didn't want my preconceived ideas of what it means to have difficulties with speech, hearing or reading to stand in the way of recognizing what the children could actually do. I recalled Vivian Paley's description of Jason, "the quintessential outsider" (1990, p. x). She wrote, "There are labels that might be attached to Jason, but we'll neither define him nor categorize him. None of us are to be found in sets of tasks or lists of attributes; we can be known only in the unfolding of our unique stories within the context of everyday events" (1990, p. xii). In Jay's case, I expected he would, with time and personal assistance, find a way to use the computer as a tool in unfolding his unique story.

Jay spent at least five minutes just staring at the composition glowing on his monitor screen. When I approached his work station he looked up and said, "Yesterday, it got all covered up." He was referring to the image of a coin he had imported from the Internet and subsequently manipulated. Along with raising his Labrador puppy, Jay also loved collecting coins and wanted to incorporate an American gold coin in his self portrait. He disliked the results from yesterday's experimentation but since he had forgotten to save the original coin image on his zip disc, he was unable to go back and generate additional variations on his theme. Jay felt another Internet search would be fruitless because he had previously discovered only a couple suitable images. When he asked me what he could do next, I presented him with a library book about collecting coins which included a section on American gold coins, his favorites. He almost smiled and began thumbing through the pages identifying the coins he knew and explaining a little about their history.

I reviewed with Jay the steps involved in scanning and saving images onto his zip disc. During previous classes Jay hesitated to ask for help or to try any of the numerous options included in the Photoshop software. Unless one of the graduate student volunteers or I intervened, Jay would often sit for long 
periods of time without doing anything. I had wondered if he was overwhelmed by the sheer number and novelty of choices or if he was fearful of making mistakes. It was an encouraging change when Jay decided which images he wanted to scan and how he might include them in his self portrait. He was for the first time at camp pursuing a self-directed course of action.

It took Jay most of the session to scan and save his favorite photographs from the library book. Toward the end of the session, Jay sat back in his chair gazing with admiration at his golden images. David, who had been intent on his own project, stopped for a moment to look at Jay's work and pronounced it "cool". Several of the other teens interrupted their work and listened as Jay and David exchanged a few more words about coin collecting. David asked how much American gold coins were worth. Although I couldn't hear Jay's reply, I remember thinking that the realvalue of his golden coin images might potentially be found as a kind of currency for helping Jay to establish his identity within the group.

At the close of the Thursday morning art class, I overheard Jay explaining to another participant the use of gold ingots during the California gold rush. His voice at that moment carried more conviction than I had observed at any other time at camp. I wondered what had contributed to Jay's newly emerging sense of ease with himself and the others around him. Mary Catherine Bateson described how she was pushed to reflect on and learn from her discomfort when encountering different cultures. I thought perhaps Jay's feelings of social isolation and homesickness had similarly pushed him toward learning new behaviors after the party at Happy Joe's. In Bateson's words, "Each person is calibrated by experience, almost like a measuring instrument for difference, so discomfort is informative and offers a starting point for new understanding" (1994, p. 17). I guessed that Jay's great sadness after the party had been the necessary discomfort which informed and offered him a new beginning. In addition, sharing the images of his prized coins provided a means to strengthen his self confidence and to reclaim a defining part of his story.

Bateson maintained that it is the business of the human community to "bring one another into being" (p. 63). Looking back I recognize some of the ways in which the staff and participants of Close Encounters helped provide the circumstances for Jay to join in and be changed by a common dance. He was supported as he reached through his shyness and isolation toward a fuller participation in the Close Encounters community. Jay was learning through experience that "personhood arises from a long process of welcoming closeness and continues to grow and require nourishment over a lifetime of participation" (p. 62). 


\section{References}

Bateson, M. C. (1994). Peripheral Visions: Learning Along the Way. New York: HarperCollins.

Buber, M. (1955). Between Man and Man. Boston, MA: Beacon Press.

Maddy, B. J. (1988). Close encounters: promoting social independence in adolescents with physical disabilities. Therapeutic Recreation Journal. Fourth Quarter: 49-55.

Paley, V. G. (1990). The Boy Who Would Be A Helicopter. Cambridge, MA: Harvard University Press.
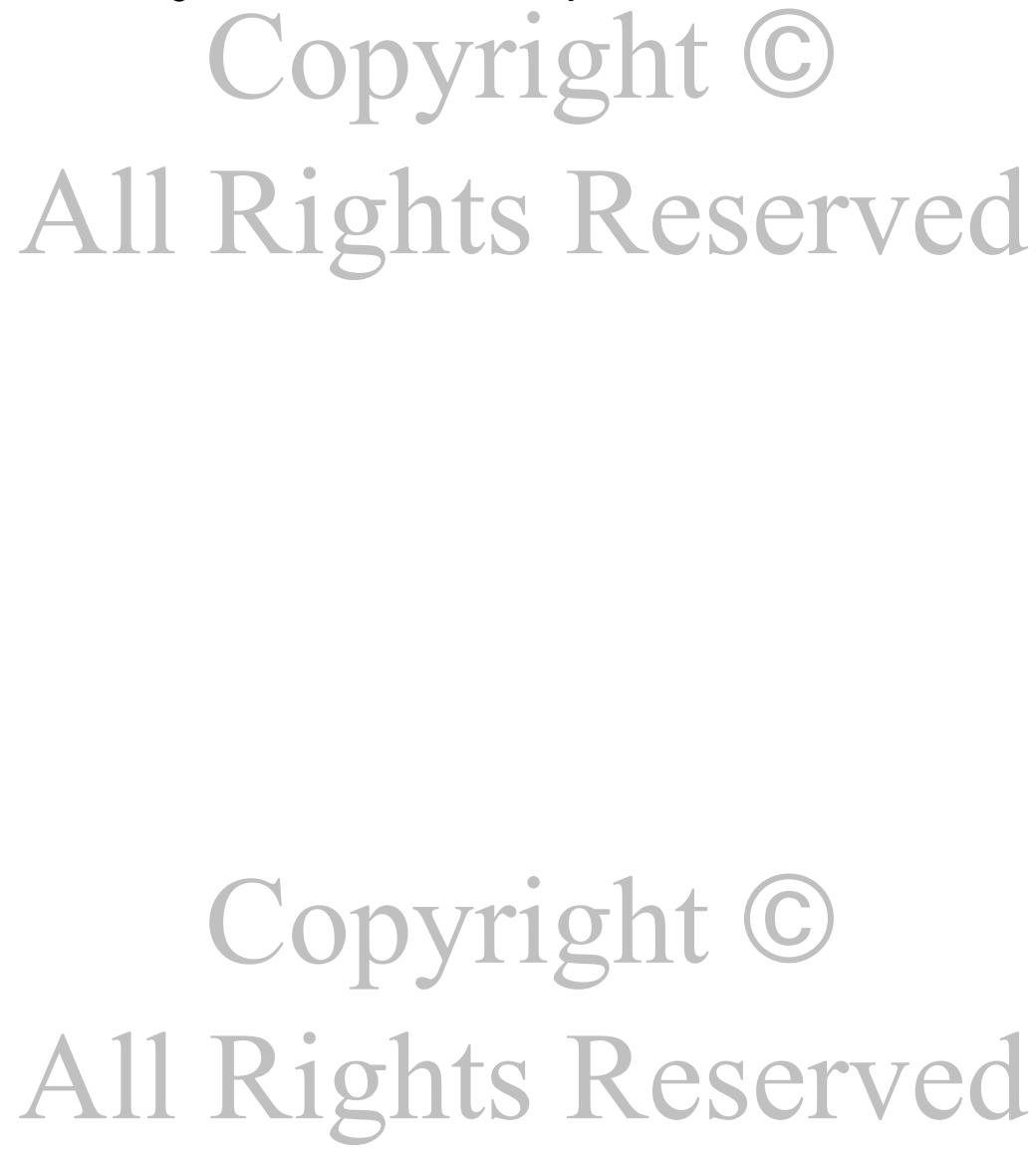